\title{
Новейшие тренды виртуализации общества: иллюзии теоретической социологии в эпоху интенсивной сверхсовременности
}

\author{
О.А. Игнатьева ${ }^{1}$, А.В. Плетнев ${ }^{2}$ \\ ${ }^{1}$ Санкт-Петербургский государственный университет, ${ }^{2}$ Санкт-Петербургский университет \\ МВД России \\ ol ga7919@mai I.ru,venger.vin@r ambler.ru
}

\section{Аннотация}

Теории, которые объясняют общество в целом, играют роль своеобразной призмы, сквозь которую научное сообщество понимает социальный мир. Они становятся частью научной картины мира и в конце концов влияют на представления каждого индивида об окружающей действительности. Если эти теории будут ошибочными, неадекватными социальной реальности, то это приведет к кризису социальной науки, неэффективности прикладных наук и неспособности людей понять происходящие в обществе перемены. Анализ возникшего в теоретической социологии кризиса мультипарадигмальности, а также происходящих в обществе процессов позволяет утверждать, что господствующие представления об обществе ошибочны, и причиной искажения теории является развитие постмодернизма. Переняв от Бодрийяра концепцию симулякра, социологи увлеклись иллюзорными идеями и упустили подлинную причину социальных изменений - формирование новой экономической формации, неокапитализма. Социологи скрупулёзно описывают следствия неокапиталимза, игнорируя причину. Среди последних постмодернистских теорий, основанных на бодрийяровской идее симуляции реальности, наиболее авангардными являются теории виртуализации. Хотя большая часть этих теорий иллюзорна, некоторые из них содержат в себе долю истины и крайне интересны с теоретической точки зрения. Новейшие тренды виртуализации свидетельствуют о том, что эта теория становится более адекватна социальной реальности.

Ключевые слова: мультипарадигмальность, теории виртуализации, поствиртуализация, симулякр, неокапитализм, аномия, дополненная реальность, сверхсовременность

Библиографическая ссылка: Игнатьева О.А., Плетнев А.В. Новейшие тренды виртуализации общества: иллюзии теоретической социологии в эпоху интенсивной сверхсовременности // Информационное общество: образование, наука, культура и технологии будущего. Выпуск 3 (Труды XXII Международной объединенной научной конференции «Интернет и современное общество», IMS-2019, Санкт-Петербург, 19 - 22 июня 2019 г. Сборник научных трудов). - СПб: Университет ИТМО, 2019. C. 160 - 169. DOI: 10.17586/2587-8557-2019-3-160-169

\section{Введение}

Господствующая в социологической теории парадигма оказывает огромное влияние как на устоявшиеся, общепризнанные теории, так и на авангардные. Любые теоретики принимают её во внимание, и она играет роль своеобразной призмы, сквозь которую ученые видят социальный мир. Эта парадигма оказывает влияние и на прикладные социальные науки, поскольку они основываются на теории, а далее на выводах прикладных наук 
основываются решения органов власти и субъектов экономки. Не будет преувеличением утверждать, что господствующая в социологии парадигма - важная часть научной картины мира, которая оказывает влияние на все общество в целом. Искажение этой парадигмы, её несоответствие действительным закономерностям социального мира будет негативно влиять на все общество. Анализ социологической теории позволяет сделать вывод, что господствующая парадигма ошибочна. Об этом свидетельствует феномен социологической мультипарадигмальности который означает, что наука не развивается, у неё нет общепризнанных определений базовых понятий. Этим же объясняется застой в теоретической социологии, поскольку в науке не появляется принципиально новых теорий, которые бы углубляли бы подлинное понимание социального мира. В место этого новые теории являются новым взглядом на известные вещи или просто констатацией происходящих в обществе изменений. Причины описанного кризиса в теоретической социологии особенно очевидны на примере теорий виртуализации, которые являются новейшими и наиболее авангардным. При этом некоторые перспективные тренды в теории виртуализации свидетельствуют о том, что в будущем эти теории могут стать более адекватны социальному миру и освободиться от теоретических иллюзий. Полное преодоление кризиса мультипарадигмальности в теоретической социологии возможно за счет осознания социологами ошибочности посмодернистской парадигмы и изучения феномена неокапитализма, как подлинной основы происходящих в обществе изменений. Развитие социологии по этому пути приведет к появлению целого класса сверхсовременных социологических теорий. Это не только исправит искажение в теории, но и сделает существенно более эффективными прикладные социальные науки, а также основанные на них государственные программы и стратегии бизнеса. Исследуемая в данной статье тема крайне актуальная и обладает характеристиками научной новизны, связывает решение фундаментальных научных проблем с новейшими тенденциями в теории. Она важна для социальной практики и имеет огромный потенциал применения в разных областях. Представленное в данной статье исследование было проведено методами реконструкции концепции и теоретического синтеза. В сфере методологии онтологическим основанием исследования выступил номинализм, а эпистемологическим - интерпретативизм.

Поскольку концепция неокапитализма является новым словом в теории литературы по ней не существует. Исходя из исследовательских целей рассмотрим литературу по смежным темам: классическому капитализму, виртуализации и обществу потребления. Современные работы, посвященные капитализму, все ещё интерпретируют мир в классической парадигме, игнорируя доминирующую роль символического потребления. По теме общества потребления написано большое количество литературы, в которой достаточно подробно и точно описаны практики статусного потребления, однако причина этого явления не раскрывается. Символическое потребление рассматривается здесь как некий тренд в рамках классического капитализма, и исследователи ограничиваются простым описанием этого феномена.

\section{1. Причины кризиса теоретической социологии}

Социологическим мейнстримом являются постмодернистские теории, основная идея которых заключается в том, что общество перешло в некое принципиально иное состояние, которое не может быть описано в координатах классической социологической теории. Однако постмодернистами это утверждение не было в достаточной степени доказано и обосновано, они не создали такой постмодернистской социологической теории и методологии, которая была бы способна заменить прежнюю. Многие постмодернистские концепции в социологии основываются на предложенной Бодрийяром идее симуляции реальности, дихотомии реального и виртуального. Предложенная постмодернистами теория составляет разрозненные утверждения об обществе. Ошибочность предложенного Бодрийяром противопоставления «реального» и «виртуального» заключается в том, что, 
говоря о социальной реальности, он оперирует понятием «реальность», характерным для физического мира. К примеру, очевидно, что такие объекты как дед мороз или единорог не существуют в физическом мире, эти слова не отсылают нас к реальным живым организмам. Однако эти вещи создают реальные социальные последствия и, значит, реальны для социологии. В итоге дихотомия Бодрийяра не имеет никакого смысла. Если осознать этот простой факт, то рушатся как карточный домик не только теоретические построения Бодрийяра, но и вся постмодернистская социология.

Наиболее очевидно это на примере теорий виртуализации, основанных на иллюзорной дихотомии «реального» и «виртуального». Концепции виртуализации А. Бюля и А. Крокера основаны на этой дихотомии и исходят из главенствующей роли технологий, компьютеризации как причины виртуализации. С позиции этого подхода виртуальная реальность - это «совокупность ощущений индивида, порожденных использованием различных технических и электронных устройств, которые способны имитировать функции объектов реального мира (зрение, слух, осязание)» [8, с. 59], а в интернете возникает симулированная реальность - киберпространство. В теории А. Бюля [5] под виртуализацией понимается замещение реально существующего объекта виртуальным аналогом. А. Крокер и М. Вейнстейн используют марксистский подход для интерпретации виртуализации и понимают её как отчуждение человека от физического тела в процессе использования компьютера [12]. Этот процесс используется для обогащения нового эксплуататорского класса - виртуального. Следует отметить, что эта теоретическая модель получена в результате изложения идей Маркса постмодернистским языком и внутренне противоречива. Владельцы цифровых корпораций, хотя и владеют виртуальными средствами производства и проводят виртуальные денежные расчёты, тем не менее являются реальными людьми и представителями вполне реального класса капиталистов. Противоположной логике следуют концепции виртуализации жизненного мира О. Олинахо и социоцентрическая концепция виртуализации Д. Иванова. Как отмечает Иванов «ориентация практик не на вещи, а на образы ведет к симуляции институтов (виртуальное следование ролям). Институты сами становятся образами, превращаясь в своего рода виртуальную реальность» [10, с. 85].

Многие постмодернисткие теории не наследуют столь явно идею противопоставления реального виртуальному, но осмысливают мир в постмодернисткой парадигме. С этой точки зрения, поскольку социальный мир является симуляцией реальности, то в нем не будет однозначной истины ни объективной, ни субъективной. Это мир постправды и постметодологии, в котором отвергаются как реалистические, так и номиналистические пути познания. Постмодернистская мысль «последовательно отвергает причины» [7, с. 81] в интерпретации социальных явлений. К постмодернистсктому направлению относятся концепции неопрагматизма Ричарда Рорти, радикального постмодернизма Жана Бодрийяра, феминистские концепции Ненси Фрейзер и Сейлы Бенхабиб, постструктуралистские теории Жана Лиотара и Жиля Делёза, концепция деконструкции Жака Дерриды, работы Мишеля Фуко. Некоторые из них не используют слово постмодернизм в своих работах, но объединяет их именно постмодернистский способ объяснения мира. Постмодернисты отталкиваются от слабых мест традиционной социологии. В итоге взгляды постмодернистов представляют собой скорее не положительные утверждения об обществе, а констатацию социальных и культурных изменений, проблем в существовании общества. Они отталкиваются от «интенции “разоблачения" модернистских построений» и формируют «альтернативное модернизму видение мира» [16, с. 39].

В целом постмодернистская социологическая мысль приходит к идее противопоставления «прежнего» общества (реального) и «нового» (симулякра). Эта идея ложна, поскольку основана на ложном противопоставлении. В реальности же современность продолжается, но в несколько ином виде. Мы живем в эпоху сверхсовременности, где работают закономерности классической социологии. 
Отличительные особенности эпохи сверхсовременности связаны с развитием экономики нового типа - неокапитализма.

\section{2. Неокапитализм как ключ к пониманию сверхсовременного общества}

Распространение в сверхсовременном обществе социального стресса и девиации заставляет усомниться в господствующем в экономической литературе понимании капитализма как производства для удовлетворения потребностей с целью получения прибыли. Многие теоретические и эмпирические факты свидетельствуют о противоположном влиянии капитализма. При анализе социологической литературы за последние три десятилетия можно заметить, что социологи вернулись к обсуждению аномии [3, p. 5] и рассматривают её как многоаспектный психосоциальный стресс [1]. Проявления этого феномена можно наблюдать на примере растущего расслоения по доходам, высокого уровня самоубийств и прочих проявлений девиантного поведения [2, p. 3], появления множество протестных движений в развитых и развивающихся странах. Все эти явления проистекают из экономики. Очевидно, что капитализм не работает в рамках той теоретической схемы, которая была предложена Карлом Марксом, Адамам Смиттом и Филипом Котлером. Вместо удовлетворения потребностей человека экономика и культура в целом порождают рост неудовлетворенности. Указанные обстоятельства порождают убеждение в том, что классические социологические концепции капитализма не работают как раньше, поскольку изменилась сущность самого капитализма.

Кризис классического капитализма связан с невозможностью бесконечного наращивания объемов производства за счет постоянного расширения рынка по той простой причине, что объем земного шара ограничен. Распад СССР и исчезновение Варшавского договора стало для транснациональных корпораций последней возможностью захватить неосвоенные рынки. Дальнейшее увеличение продаж и прибыли было возможно только за счет качественного, а не количественного наращивания потребления. С большой долей условности момент падения Берлинской стены можно считать тем моментом, когда начал формироваться неокапитализм. Качественное наращивание потребления означает что вещи необходимо продать тем потребителям, у которых эти вещи уже есть. В данном случае потребителю предлагается не сам товар, а ассоциируемый с ним символический статус. К примеру человек, владеющий исправным автомобилем, не заинтересован в приобретении нового, однако его заинтересует возможность получить статус богатого [13, p. 22], уважаемого, спортивного, сексуального члена общества. Этот статус может ему дать новый товар, произведенный престижным брендом и соответствующий господствующим на рынке потребительским трендам. К примеру, новый автомобиль марки Проше может существенно улучшить настроение того, кто его приобрел, и также существенно ухудшить настроение окружающих, которым он не по карману [14, p. 470]. Практики символического потребления не только повышают социальный статус индивида, но и приносят ему огромное эмоциональное удовольствие [4, p. 312].

Благодаря развитию потребления, выходящего за рамки практических соображений, формируется неокапитализм - тип формации или экономической культуры, основой которого является символическое потребление. Развитие неокапитализма оживляет экономику, но оно крайне губительно для общества. При этой формации планка необходимого потребления постоянно повышается. Каждый год или каждый сезон внутри года происходит обновление трендов на рынке, и имеющиеся у потребителя вещи перестают быть соответствующими моде и представлениям о необходимом достатке. В результате потребитель вынужден покупать новые вещи по причине их «морального устаревания». Эта гонка за потреблением приводит к тому, что даже люди со средним достатком постоянно ощущают себя нуждающимися, берут кредиты для покупки трендовых вещей. Для обозначения подобных людей социолог Д.В. Иванов ввел крайне 
удачный термин - сверхновые бедные [9, с. 24]. В итоге положение этих, вполне обеспеченных финансовыми средствами людей, напоминает положение бедняков в условиях классического капитализма. Следует отметить, что эти явления социальной жизни так или иначе уже описаны в многочисленных публикациях по маркетингу и обществу потребления. Но скрупулёзно перечисляя многочисленные симптомы формирования сверхновой экономики, социологи и экономисты упустили главное - причину происходящих событий - становление новой формации.

Появление сверхновой бедности является не случайным феноменом, оно систематически генерируется субъектами экономики. Для стимулирования и поддержания стремления индивидов к символическому потреблению необходимо переориентировать их на потребительские ценности в ущерб подлинным ценностям, таким как семейные, религиозные, национальные и пр. Процесс распада подлинных ценностей ранее был блестяще концептуализирован Мертоном как процесс аномии, когда повышающиеся требования культуры к финансовому успеху индивидов не обеспечиваются возможностями реальной экономики. Это определение оказалось крайне удачным, что позволяет ему преобладать в социологии уже более полувека, однако оно описывает суть аномии, на касаясь её причин. Концепция Мертона не позволяет понять, почему повышаются требования культуры к материальному успеху индивидов, и она не способна объяснить повышения аномии и интереса социологов к этому явлению в течение последних трех десятилетий.

Если в условиях классического капитализма аномия представлялась социологам как маргинальное явление социальной жизни, то в неокапитализме она играет роль двигателя. В этих условиях реклама, кинематограф, СМИ и прочие элементы массовой культуры, с одной стороны, генерируют аномию, которая разрушает традиционные ценности, а с другой, навязывают индивидам ценности статусного потребления. Развитие аномии приводит к повышению уровня девиации и преступности [15, p. 187], эта связь была обнаружена еще Дюркгеймом, а описание повышения уровня преступности в эпоху неокапитализма можно обнаружить в криминологической литературе, начиная со знаменитого труда о преступности и американской мечте. Несмотря на огромную ценность этих работ для теории и практики, они опять же описывают следствия, а не причину. Современная криминология может стать существенно эффективнее, если будет учитывать феномен неокапитализма.

Если все предыдущие формации, согласно Марксу, приводило в движение развитие производительных сил, то неокапитализм развивается благодаря развитию символического потребления. Совершенствование вещей как физического носителя символического статуса имеет второстепенное значение. Главной составной частью общественной жизни становится не материальное производство, а символическое потребление. Постоянная гонка людей за статусным потреблением и финансовая неспособность удовлетворить эту потребность порождают целостную депрессивную культуру. Огромное изобилие созданных товаров и услуг парадоксальным образом привело не к удовлетворению потребностей, а к ощущению хронической неудовлетворенности индивида.

В неокапиталистическом обществе находятся индивиды, которые отказываются следовать потребительским ценностям, даже начинают борьбу с потребительским стилем жизни. Они отвергают неокапитализмом, подвергая критике символическое потребление. Эти индивиды приобретают дешевые товары, которые имеют тот же функционал, что и продукция известных брендов. Они любят высмеивать поклонников дорогих и статусных товаров называя их людьми, которые напрасно тратят деньги. Хотя такие индивиды могут активно пропагандировать свои взгляды, они не только не мешают функционированию неокапитализма, но и играют в его функционировании системную роль. Они играют роль своеобразного противовеса по отношению к поклонникам брендов и трендов. Поскольку престиж продукции любого известного бренда обратно пропорционален количеству людей, способных её приобрести, то для поддержания этого престижа необходимы потребители, 
которые не хотят или не могут купить эту продукцию. Престиж является результатом сравнения статусных позиций различных товаров, и богатые могут считаться богатыми только по отношению к бедным. Если продукция определенного бренда становится слишком распространена на рынке, то такой бренд теряет свои статусные позиции, и из продукции для богатых он может превратиться в продукцию, которая не обеспечивает её владельцу символического статуса. В итоге потребители дешевых и функциональных товаров оказываются нужны в неокапиталистической экономике.

Помимо этого, оказываются бесполезными работы социологов и экономистов, критикующих негативные проявления неокапитализма. На практике правительства большинства стран ориентируются при принятии решений на потребности крупного капитала, а крупный капитал функционирует по законам неокапитализма. Получается, что и правительства не препятствуют развитию неокапитализма.

Далее рассмотрим некоторые особенности неокапитализма, которые позволяют считать его отдельной формацией или новым типом экономической культуры, отличным от прежнего капитализма. Прежде всего, в эпоху неокапитализма исчезает самый главный недостаток прежнего капитализма - эксплуатация. Это связано с тем, что значительная часть цены престижного товара оставляет символический компонент. Стоимость товара как физического носителя может быть в несколько раз меньше, чем цена на витрине магазина. Это означает, что большая часть прибыли компании, создается не в рабочем цеху, а в кабинете маркетолога. В этом смысле уместно задаться вопросом, кто кого эксплуатирует в наиболее престижных корпорациях, капиталист наемного работника или наоборот? Возможно многие рабочие в престижных корпорациях получают большую оплату, чем подразумевает их вклад в производство. Дополнительным свидетельством сказанного является появление категории «золотых воротничков» внутри класса наемных работников. Огромные доходы представителей этой группы связаны с тем, что их творческие идеи позволяют компаниям получать миллионные сверхдоходы.

Другой особенностью классического капитализма, которая исчезает в эпоху неокапитализма, является отчуждение. С одной стороны, работник, по-прежнему, отчуждается от произведенного продукта, но с другой стороны, он приобщается к символическому статусу компании. Принадлежность к престижному бренду сама по себе поднимает социальный статус работника. Теряет смысл также и понятие прибавочной стоимости, поскольку производители наиболее престижных брендов могут вообще не брать в расчёт себестоимость товара.

\section{3. Новейшие тренды виртуализации}

Теории виртуализации и цифрового общества описывают не суть процесса, не новую реальность, а только одну из сфер общественной жизни. Виртуальная реальность не приходит вместо социальной реальности и не существует параллельно как отдельное общество. Вместо этого интернет и виртуальные взаимодействия существуют как элементы дополненной реальности «Augmented Reality». Они не делают иллюзорными реальные социальные взаимодействия, но дополняют их. Таким образом, главным трендом виртуализации общества является появление виртуализации нового типа, которая соответствует интернету поколения Web 4.0 дополненная реальность. Виртуализация Web 4.0 «Augmented Reality» - это тип социального взаимодействия, при котором объекты физического мира дополняются виртуальными объектами, незамедлительно оказывающими влияние на взаимодействие в физическом мире. Описанный тренд является перспективным и только еще зарождается. Виртуализация как дополненная реальность является как новой технологией, так и сверхновой социологической концепцией. Элементы дополненное реальности уже сейчас окружают человека повсюду. Так, например, изображение виртуальной карты города на навигаторе, показывающие водителю автомобиля направление движения, существует не в киберпространстве, а в пространстве 
физическом и оказывает непосредственное влияние на процессы в физическом мире - езду автомобиля. Со временем элементов дополненной реальности будет становиться все больше, и это будет проанализировано социологами.

И хотя в научной литературе нередко можно встретить публикации, посвященные феномену дополненной реальности, большая часть из них характеризуется абсолютным непониманием социологического смысла этого явления. Дополненную реальность воспринимают просто как очередную популярную технологию $[11$, с.94] и оценивают её потенциал с точки зрения бизнеса, или как модный тренд социальной жизни, который быстро пройдет и о нем забудут [7, с. 54]. Однако концепция дополненной реальности Web 4.0 - это концепция, которая описывает значительную часть социального взаимодействия в будущем. Аналогичным образом интернет поколения Web 3.0 не исчез и продолжает существовать как важнейший фактор, сильно влияющий на все общество. По сути, мы наблюдаем ещё только зарождение этого тренда, огромный потенциал которого не оценило ни научное, ни профессиональное сообщество.

В сфере теории же мы можем наблюдать застой, и это является вторым, актуальным в настоящее время, трендом виртуализации. Появляются новые публикации по этой теме и конструируются концепции, однако это не означает появления принципиально новых парадигм. Все фундаментальные идеи в области виртуализации были придуманы в 90 -е годы XX века, и с тех пор прошло уже два десятилетия. Появляются новые теоретические конструкты, такие как «поствиртуализация», «посглобализация» или «виртуализация жизненного мира». Но в этих конструктах нет ничего принципиально нового, они исходят все из того же противопоставления категорий «реальное» и «виртуальное».

Третьим трендом виртуализации является виртуализация денежного обращения. Речь идет не о расчётах через Интернет или подобных технологиях, а о появлении принципиально нового типа валюты - криптовалюты. Существование криптовалюты обусловлено как феноменом виртуализации, так и феноменом неокапитализма. Если благодаря вируализации оборот криптовалюты происходит в виртуальном пространстве, без физического носителя, то неокапитализм обуславливает принципиально новую онтологию этого вида денежных средств. Все прочие меры стоимости, которые используются для обмена на рынке, имеют реальный эквивалент. Их стоимость обусловлена объемом ВВП, объемом золотовалютных резервов, уровнем добычи золота в мире и так далее. Все эти меры стоимости связаны с реальными физическими вещами. Стоимость же криптовалюты обусловлена исключительно ожиданиями, верой потребителя в то, что криптовалюта стоит реальных денег. Производители биткойна не имеют золотовалютных резервов, эта криптовалюта не обеспечена произведенными товарами и услугами. Криптовалюта - это виртуальные деньги, деньги неокапитализма. В парадигме классического капитализма было бы трудно объяснить потребителям и инвесторам почему цифровая запись должна чего-то стоить. Однако в экономике неокапитализма, где цена самых дорогих вещей многократно больше их себестоимости, вполне логично пользоваться мерой товарного обмена, курс которой виртуален и определяется только ожиданиями.

\section{Заключение}

В результате проведенного исследования было выявлено и обосновано несоответствие постмодернистской парадигмы действительным закономерностям социальной реальности. Ложная идея симуляции реальности привела к искажению всей теоретической социологии, а затем и общей научной картины мира. Выявление этого теоретического искажения потенциально может внести существенный вклад в теоретическую отрасль социологического знания, поскольку показывает направление преодоления кризиса социологической мультипарадигмальности. В ходе исследования также предложена концепция неокапитализма как новой формации, которая объясняет сущность экономики эпохи сверхсовременности. Эта концепция дает целостное объяснение экономических и 
социальных закономерностей, глубинное понимание механизмов производства смыслов в то время, как в существующей литературе можно обнаружить фрагментарные объяснения, посвященные только отдельным аспектам неокапиталистической экономики. Искажение господствующей в социологии парадигмы было подробно рассмотрено на примере теории виртуализации, в которой были выявлены новейшие тренды. Актуальными и очевидными трендами являются застой, стагнация теоретической мысли в этой сфере и виртуализация денежного обращения. Потенциальным трендом, трендом будущего является формирование виртуализации как дополненной реальности, соответствующей интернету поколения Web 4.0. Проведенное исследование показывает путь преодоления кризиса социологической мультипарадигмальности, и этот результат имеет огромное значение для теоретической социологии.

Полученные в ходе исследования результаты хоть и относятся сфере теории, но имеют огромный потенциал для применения в различных областях социальной практики. Прежде всего этот потенциал связан с механизмом функционирования неокапитализма, который разрушает подлинные ценности за счет аномии и навязывает индивиду ценности символического потребления. Возникающая аномия приводит к широкому спектру проявлений девиантного и преступного поведения, возникновения психосоциального стресса и чувства неудовлетворенности. Возможности для преодоления девиации будут интересны криминологам, социальным работникам, педагогам и многим другим специалистам. Понимание механизма функционирования неокапитализма будет полезно маркетологам, специалистам по рекламе, дизайнерам и иным специалистам, заинтересованным в налаживании маркетинговых коммуникаций и увеличении продаж.

\section{Литература}

[1] Agnew R., Kaufman J. M. Anomie, Strain and Subcultural Theories of Crime. London: Routledge, 2016.

[2] Atteslander P., Gransow B., Western J. Comparative Anomie Research: Hidden Barriers Hidden Potential for Social Development. London: Routledge, 2019.

[3] Baumer E. P. Anomie: Oxford Bibliographies Online Research Guide. Oxford university press, 2010.

[4] Berta P. Materializing Difference: Consumer Culture, Politics, and Ethnicity among Romanian Roma. Toronto: University of Toronto Press, 2019.

[5] Buhl A. Die Virtuelle Gesellschaft. Opladen: Westdeutscher Verlag, 1997.

[6] Глазкова С. А. Технология дополненной реальности в современном художественном пространстве // Визуальная коммуникация в социокультурной динамике: сборник статей международной научно-практической конференции (23 октября 2014 г). Казань, 2015. C. 49-55.

[7] Hicks S. R. C. Explaining. Postmodernism. Skepticism and Socialism from Rousseau to Foucault. Ockham's Razor; Expanded edition, 2011.

[8] Добринская Д.Е. Киберпространство: территория современной жизни // Вестник Московского университета. Серия 18. Социология и политология. 2018. Том. 24. № 1. C. 52-70.

[9] Иванов Д.В. Глэм-капитализм: общество потребления в XXI веке // Журнал социологии и социальной антропологии. 2011. Т. 14. № 5. С. 9-28.

[10]Иванов Д.В. Виртуализация общества. СПб.: Петербургское Востоковедение, 2000.

[11]Иванова А.В. Технологии виртуальной и дополненной реальности: возможности и препятствия применения // Стратегические решения и риск-менеджмент. 2018. № 4. C. 88-107.

[12]Kroker A., Weinstein M. Data trash. The theory of the virtual class. Montreal: New World Perspectives, 1994.

[13]Maison D. The Psychology of Financial Consumer Behavior. Springer, 2019. 
[14]Sethna Z., Blythe J. Consumer Behaviour. SAGE Publications Ltd., 2019.

[15]Siegel L. J. Criminology: The Core. USA. Boston: Cangage, 2017.

[16]Чудова И. А. Постмодернизм и социологическая теория // Социологические исследования. 2015. № 5. С. 33-41.

\title{
The Latest Trends in the Virtualization of Society: the Illusions of Theoretical Sociology in an Era of Intense Supermodernity
}

\author{
O.A. Ignatjeva ${ }^{1}$, A.V. Pletnev ${ }^{2}$
}

\section{${ }^{1}$ St Petersburg State University, ${ }^{2}$ St Petersburg University of Internal Affairs Ministry}

Theories that explain society as a whole play the role of a unique prism through which the scientific community understands the social world. They become part of the scientific picture of the world and ultimately influence each individual's ideas about the surrounding reality. If these theories are erroneous, inadequate in social reality, this will lead to a crisis in social science, the ineffectiveness of applied sciences and the inability of people to understand the changes taking place in society. Analysis of the multiparadigm crisis that has arisen in theoretical sociology, as well as the processes occurring in society, suggests that the dominant ideas about society are erroneous and the reason for the distortion of the theory is the development of postmodernism. Having adopted the concept of simulacra by sociologists from Baudrillard, sociologists took a great interest in illusory ideas and missed the real reason for social change - the formation of a new economic formation, neo-capitalism. Sociologists meticulously describe the consequences of neocapitalism, ignoring the cause. Among the latest postmodern theories based on Baudrillard's idea of simulating reality, theories of virtualization are the most avant-garde. Although most of these theories are illusory, some of them contain a grain of truth and are extremely interesting from a theoretical point of view. The latest virtualization trends indicate that this theory is becoming more adequate to the social reality. The work considers the main trends of virtualization in terms of supermordernity.

Keywords: multi-paradigm, virtualization theories, post-virtualization, simulacrum, neocapitalism, anomie, augmented reality, supermodernity

Reference for citation: Ignatjeva O.A., Pletnev A.V. The Latest Trends in the Virtualization of Society: the Illusions of Theoretical Sociology in an Era of Intense Supermodernity // Information Society: Education, Science, Culture and Technologies of the Future. Vol. 3 (Proceedings of the XXII International Joint Scientific Conference «Internet and Modern Society», IMS-2019, St. Petersburg, June 19-22, 2019). - St. Petersburg: ITMO University, 2019. P. 160 - 169. DOI: $10.17586 / 2587-8557-2019-3-160-169$

\section{Reference}

[1] Agnew R., Kaufman J. M. Anomie, Strain and Subcultural Theories of Crime. London: Routledge, 2016.

[2] Atteslander P., Gransow B., Western J. Comparative Anomie Research: Hidden Barriers Hidden Potential for Social Development. London: Routledge, 2019.

[3] Baumer E. P. Anomie: Oxford Bibliographies Online Research Guide. Oxford university press, 2010.

[4] Berta P. Materializing Difference: Consumer Culture, Politics, and Ethnicity among Romanian Roma. University of Toronto Press, 2019.

[5] Buhl A. Die Virtuelle Gesellschaft. Opladen: Westdeutscher Verlag, 1997.

[6] Glazkova S. A. Tehnologija dopolnennoj real'nosti v sovremennom hudozhestvennom prostranstve [Augmented reality technology in modern art space] // Vizual'naja 
kommunikacija v sociokul'turnoj dinamike: sbornik statej mezhdunarodnoj nauchnoprakticheskoj konferencii [Visual communication in socio-cultural dynamics: a collection of articles of the international scientific-practical conference]. Kazan', 2015. P. 49-55.

[7] Hicks S. R. C. Explaining. Postmodernism. Skepticism and Socialism from Rousseau to Foucault. Ockham's Razor; Expanded edition, 2011.

[8] Dobrinskaja D.E. Kiberprostranstvo: territorija sovremennoj zhizni [Cyberspace: the territory of modern life] // Vestnik Moskovskogo universiteta. Serija 18. Sociologija i politologija. 2018. Tom. 24. № 1. [Bulletin of Moscow University. Series 18. Sociology and political science. 2018. Vol. 24. \# 1]. P. 52-70.

[9] Ivanov D.V. Gljem-kapitalizm: obshhestvo potreblenija v XXI veke [Glam capitalism: a consumer society in the 21 st century] // Zhurnal sociologii i social'noj antropologii. 2011. T. 14. № 5. [Journal of Sociology and Social Anthropology. 2011. Vol. 14. \# 5]. P. 9-28.

[10]Ivanov D.V. Virtualizacija obshhestva [Virtualization of society]. St. Petersburg: Peterburgskoe Vostokovedenie [Oriental Studies], 2000.

[11]Ivanova A.V. Tehnologii virtual'noj i dopolnennoj real'nosti: vozmozhnosti i prepjatstvija primenenija [Virtual and Augmented Reality Technologies: Possibilities and Obstacles of Application] // Strategicheskie reshenija i risk-menedzhment [Strategic decisions and risk management]. 2018. № 4. P. 88-107.

[12]Kroker A., Weinstein M. Data trash. The theory of the virtual class. Montreal: New World Perspectives, 1994.

[13]Maison D. The Psychology of Financial Consumer Behavior. Springer, 2019.

[14]Sethna Z., Blythe J. Consumer Behavior. SAGE Publications Ltd., 2019.

[15]Siegel L. J. Criminology: The Core. USA. Boston: Cangage, 2017.

[16]Chudova I. A. Postmodernizm i sociologicheskaja teorija [Postmodernism and sociological theory] // Sociologicheskie issledovanija [Sociological studies]. 2015. № 5. P. 33-41. 